\title{
Neonatal opioid withdrawal and antenatal opioid prescribing
}

\author{
Suzanne D. Turner MBS MD, Tara Gomes MHSc, Ximena Camacho MMath, Zhan Yao MD MS, \\ Astrid Guttmann MDCM MSc, Muhammad M. Mamdani PharmD MPH, David N. Juurlink MD PhD, \\ Irfan A. Dhalla MD MSc
}

\section{Abstract}

Background: The incidence of neonatal opioid withdrawal is increasing in both Canada and the United States. However, the degree to which the treatment of pain with opioids, rather than the misuse of prescription opioids or heroin, contributes to the prevalence of neonatal opioid withdrawal remains unknown.

Methods: We conducted a retrospective, population-based, cross-sectional study between 1992 and 2011 in Ontario with 2 objectives. First, we determined the annual incidence of neonatal abstinence syndrome. Second, using data from a subset of women eligible for publicly funded prescription drugs, we determined what proportion of women who deliver an infant with neonatal abstinence syndrome were given a prescription for an opioid before and during pregnancy.

Results: The incidence of neonatal abstinence syndrome in Ontario increased 15 -fold during the study period, from 0.28 per 1000 live births in 1992 to 4.29 per 1000 live births in 2011. During the final 5 years of the study, we identified 927 deliveries of infants with neonatal abstinence syndrome to mothers who were public drug plan beneficiaries. Of these mothers, $67 \%$ had received an opioid prescription in the 100 days preceding delivery, including $53.3 \%$ who received methadone, an increase from $28.6 \%$ in the interval spanning 1 to 2 years before delivery $(p<0.001)$. Prescription for nonmethadone opioids decreased from $38 \%$ to $17 \%(p<0.001)$.

Interpretation: The incidence of neonatal opioid withdrawal in Ontario has increased substantially over the last 20 years. Most of the women in this cohort who delivered an infant with neonatal abstinence syndrome had received a prescription for an opioid both before and during their pregnancy.

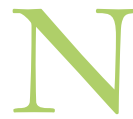
ewborns exposed to opioids in utero often undergo opioid withdrawal shortly after birth. ${ }^{1,2}$ The associated clinical findings primarily relate to the effects of opioid withdrawal on the central nervous system (e.g., tremors, irritability, increased crying, myoclonus and seizures), gastrointestinal tract (e.g., poor feeding, vomiting, diarrhea and consequent intravascular volume depletion) and the autonomic nervous system (e.g., diaphoresis, temperature dysregulation and tachypnea). Collectively, these clinical findings are referred to as neonatal abstinence syndrome, a term that also applies to signs of withdrawal from other drugs such as antidepressants, benzodiazepines and alcohol. ${ }^{1}$ Infants born to mothers who misuse opioids are more likely to be premature, have low birth weight and have higher mortality. ${ }^{3,4}$ Neonatal opioid withdrawal often necessitates care in a neonatal intensive care unit (NICU), although a spectrum of severity exists, and the resulting mother-infant separation may have a negative impact on attachment between mother and child. ${ }^{5}$ Primarily for these reasons, but also because of the economic implications of increased health services use, ${ }^{6}$ the prevention of neonatal opioid withdrawal has become a public health priority. ${ }^{7-9}$

Historically, the opioids most commonly responsible for neonatal opioid withdrawal have been heroin and methadone. ${ }^{10,11}$ In the last 20 years, coincident with the increased prescribing of opioids for chronic noncancer pain, ${ }^{12}$ several studies have documented an increased incidence of neonatal abstinence syndrome. ${ }^{6,8,13,14}$ However, no large studies have examined antenatal opioid prescription records, and the degree to which the treatment of pain with opioids contributes to the present-day incidence of neonatal abstinence syndrome is unknown.

Competing interests: See end of the article.

This article has been peer reviewed.

Correspondence to: Suzanne Turner, turnersu@smh.ca

CMAJ Open 2015.DOI:10.9778/cmajo.20140065 
We sought to determine trends in the annual incidence of neonatal abstinence syndrome in Ontario during a 20-year period. In addition, in a relevant and contemporary subset of the population for which data on antenatal prescription drug use was available, we sought to determine the proportion of mothers of infants with neonatal abstinence syndrome who received treatment with prescription opioids before and during pregnancy. Among the mothers in this secondary cohort, we compared demographics and health care use of those prescribed opioids with those who were not. Finally, we compared the health care use and health outcomes of the corresponding infants.

\section{Methods}

\section{Setting}

We conducted a retrospective, population-based study involving all live births between Jan. 1, 1992, and Dec. 31, 2011, in Ontario, Canada. Ontario is an ethnically diverse province with a population of more than 13 million people, all of whom have public coverage for physician and hospital services. Prescription data are available for people aged 65 years and older and for younger people eligible for publicly funded prescription drug coverage (primarily because of low socioeconomic status).

\section{Sources of data}

We acquired data on all hospital admissions from the Canadian Institute for Health Information Discharge Abstract Database, records of prescription medications dispensed to beneficiaries of the public drug plan from the Ontario Drug Benefit Database, demographic data from the Registered Persons Database, data from emergency department visits from the National Ambulatory Care Reporting System, and information on all inpatient and outpatient physician services from the Ontario Health Insurance Plan database. We linked the databases using encrypted anonymous identifiers. These databases have been shown to be complete and of high quality, and are routinely used to study the safety and effectiveness of prescription medications. ${ }^{15-18}$

\section{Participants}

\section{Primary cohort}

We identified all infants with a diagnosis of neonatal abstinence syndrome on their hospital discharge record, either during their stay in hospital after delivery or on readmission, during the study period (code 779.5 from the clinical modification of the International Classification of Diseases, 9th revision, from Jan. 1, 1992, to Mar. 31, 2002; code P961 from the International Statistical Classification of Diseases and Related Health Problems, 10th revision, from Apr. 1, 2002, to Dec. 31, 2011). From Apr. 1, 2002, onward, infants were matched to mothers using a unique maternal-infant matching number. Before this date, the records of mothers and infants were linked by matching the hospital of admission with admission and discharge dates. This algorithm, when applied to births after 2002, has a sensitivity of $96 \%$ and a specificity of $99 \%$, and has been used previously for research purposes..$^{19,20}$

\section{Secondary cohort}

Using data from a subset of the main cohort, we examined antenatal prescription drug use in a contemporary (20072011) population for whom such data were available by examining the prescription drug records of women who were public drug plan beneficiaries. Most of these women were recipients of social assistance in the form of welfare payments or disability support payments. Because many women avoid prescription drugs during pregnancy, we used the period between 101 and 365 days before delivery to determine whether a woman had received publicly funded prescription drugs. We used this period to ensure that each mother had continuous eligibility for publicly funded prescription drugs during the 100 days before delivery; in so doing, we minimized the risk of overestimating the rate of opioid prescribing in the period immediately before birth.

\section{Opioid prescribing before delivery}

We examined prescriptions dispensed to women who were eligible for publicly funded prescription drugs at the time of delivery and who delivered an infant with a diagnosis of neonatal abstinence syndrome during the last 5 years of the study period. We focused on this period to better understand contemporary opioid-prescribing patterns among mothers of these infants. For each mother, we examined antenatal prescribing during 3 time periods: 100 days before delivery, 101365 days before delivery and 1-2 years before delivery. We included both methadone and nonmethadone opioids (excluding buprenorphine), but considered methadone separately because it is much more commonly used for opioid dependence than for the treatment of chronic noncancer pain in Canada. Buprenorphine-containing products were not on the public formulary during the period studied. Pregnant patients with a contraindication to methadone would have been eligible for coverage of buprenorphine through a federal exemption, but these data were unavailable to us. In addition, because methadone was widely considered as the "gold standard" during the study period, very few women would have been given buprenorphine. In the 100 days preceding delivery, we also examined prescriptions for other psychotropic drugs, including sedative-hypnotic agents, barbiturates, anticonvulsant drugs, cyclic antidepressants, noncyclic antidepressants, antipsychotic agents, psychostimulants and lithium.

\section{Demographic characteristics, health care use and outcomes}

We compared demographic characteristics among mothers of infants with a diagnosis of neonatal abstinence syndrome between 2007 and 2010 (to allow 1 yr follow-up) who were eligible for publicly funded prescription drugs at the time of delivery. In addition, we compared characteristics of women who had received prescriptions for opioids during the 100 days before delivery with those who had not received such prescriptions during this period. We also compared the health care use and outcomes of the corresponding infants. Specifically, we examined the infant's gestational age at birth, birth weight and sex, in addition to length of stay in hospital, physi- 
cian visits, mortality, maternal age, method of delivery (vaginal or cesarean birth) and neighbourhood income quintile.

\section{Statistical analysis}

We calculated the incidence of neonatal abstinence syndrome for each year of the study period expressed as the rate per 1000 live births. We used the McNemar test to compare opioid prescribing among public drug plan beneficiaries between the different antenatal periods. We compared demographic characteristics, health care use and outcomes using $\chi^{2}$ tests for categorical variables and the Kruskal-Wallis test for continuous variables. We used SAS software, version 9.3 (SAS Institute) for all analyses.

\section{Results}

\section{Incidence of neonatal abstinence syndrome}

We identified 3086 infants in Ontario with a diagnosis of neonatal abstinence syndrome during the study period. The population incidence increased from 0.28 per 1000 live births in 1992 to 4.29 per 1000 live births in 2011, representing a 15 -fold increase in incidence in 2 decades. Most of this increase occurred during the last 5 years of the study period (Figure 1).

\section{Antenatal opioid prescribing}

During the last 5 years of the study period, 1901 infants were born with neonatal abstinence syndrome. Nearly half of these infants $(n=930)$ were born to 884 women who were eligible for publicly funded prescription drugs at the time of delivery.
There were 3 pairs of twins among the 930 infants, resulting in 927 separate deliveries during this 5 -year period

In each of the 3 antenatal periods we studied, most of the women in the secondary cohort received 1 or more prescriptions for an opioid: $67 \%$ of women received at least 1 prescription in the 1-2 years preceding delivery, $81 \%$ in the period between 1 year and 100 days before delivery and $70 \%$ in the 100 days before delivery (Figure 2). We saw a shift

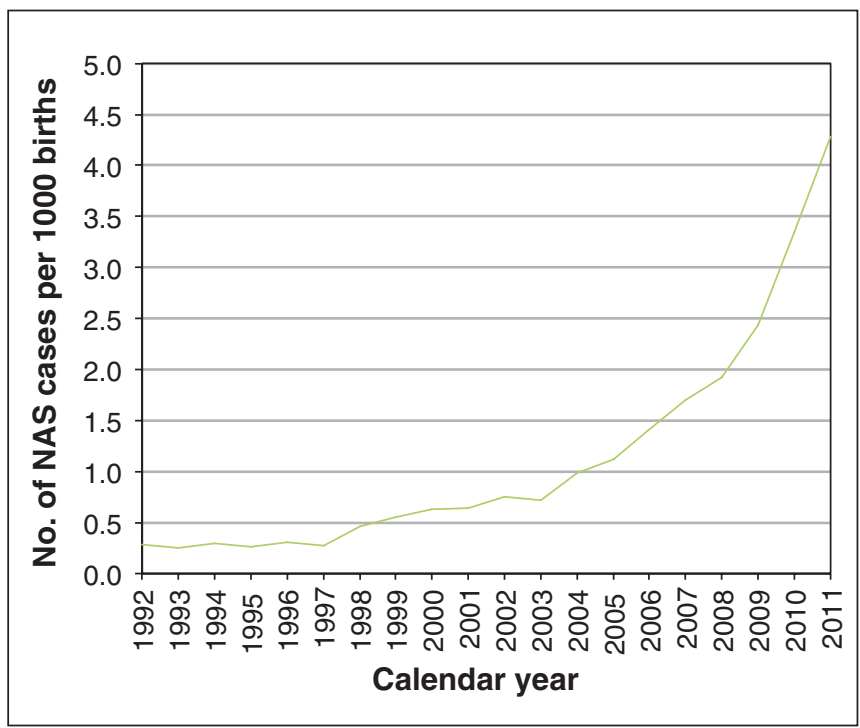

Figure 1: Annual incidence of neonatal abstinence syndrome in Ontario, 1992-2011. NAS = neonatal abstinence syndrome.

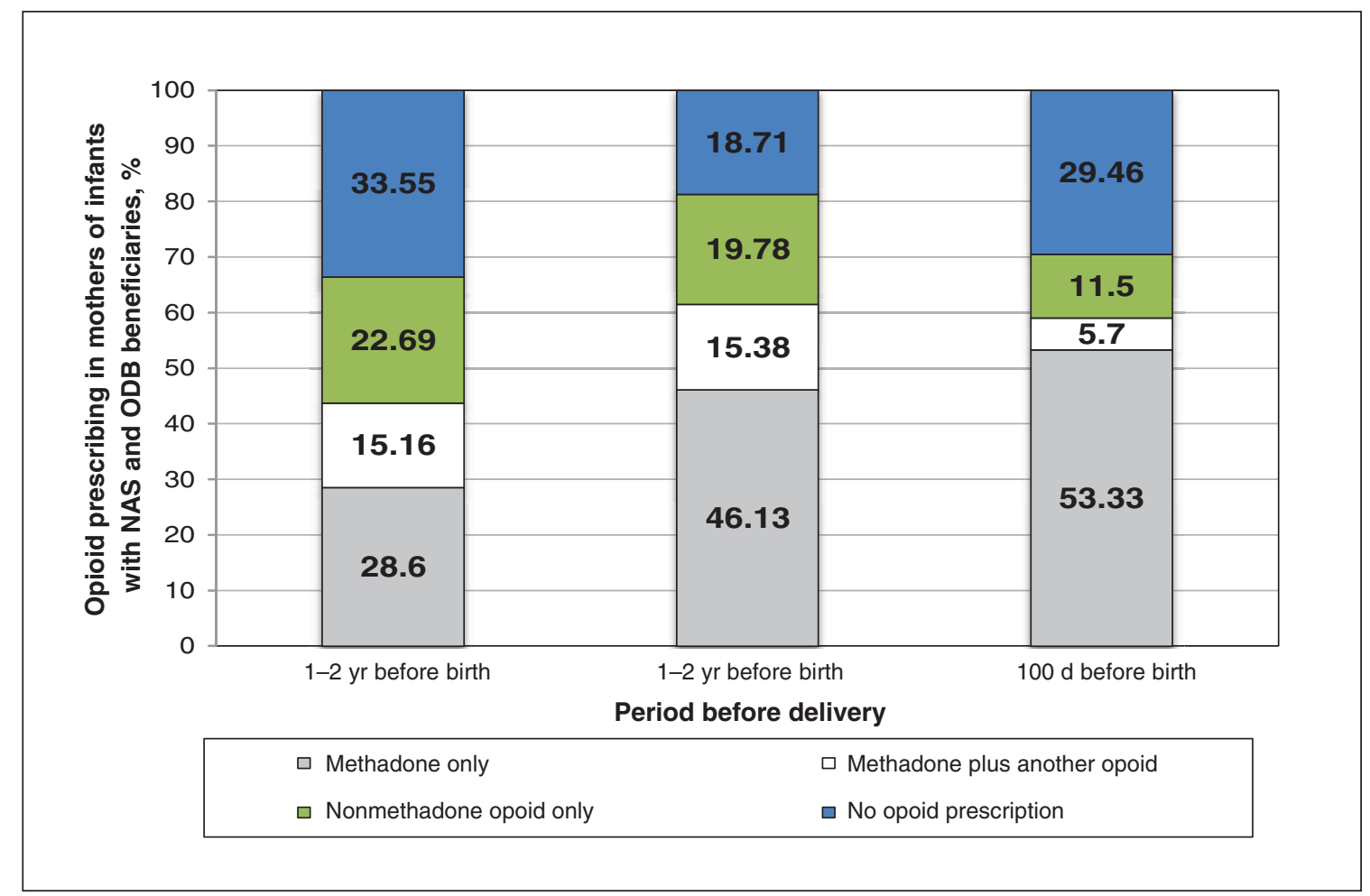

Figure 2: Opioid prescribing 1 to 2 years, 100 days to 1 year and 100 days before delivery in mothers of infants with a diagnosis of neonatal abstinence syndrome between 2007 and 2011 ( $n=927$ deliveries). ODB = Ontario drug benefit. 


\section{OPEN}

from other opioids to methadone as delivery approached. The proportion of women given prescriptions for methadone increased from $28.6 \%$ at $1-2$ years before delivery to $53.3 \%$ in the 100 days before delivery $(p<0.001)$. Conversely, the proportion of women given a prescription for a nonmethadone opioid (excluding buprenorphine) decreased from $22.7 \%$ at $1-2$ years before delivery to $11.5 \%$ in the 100 days before delivery $(p<0.001)$.

More than half $(53.4 \%)$ of the women in the secondary cohort received a prescription for a psychotropic medication in the 1-2 years before pregnancy (Table 1). The most common psychotropic medications prescribed during this period were sedative-hypnotic agents $(26.6 \%)$ and noncyclic antidepressants (35.0\%). For both of these drug classes, the percentage of women filling their prescriptions decreased as pregnancy progressed.

\section{Health service use and health outcomes}

Data were available for 618 deliveries of infants with neonatal absence syndrome born to mothers who were beneficiaries of the public drug plan between Jan. 1, 2007 and Dec. 31, 2010 (Table 2). Infants with neonatal abstinence syndrome born to mothers who received prescriptions for opioids in the
100 days preceding delivery had a longer length of stay in hospital (median of $19 \mathrm{v} .10 \mathrm{~d}, p<0.001$ ) and more outpatient physician encounters during the year after birth (median $25 \mathrm{v}$. 17 visits, $p<0.001$ ) compared with infants born to women who had not received prescriptions for opioids (Table 2). We found no difference in birth weight, gestational age at the time of delivery or sex of the infant, and very few of the infants died during the year after birth. Women who received prescriptions for opioids during the 100 days before delivery were more likely to undergo a cesarean delivery $(30.2 \% \mathrm{v}$. $21.8 \%, p=0.03)$.

\section{Interpretation}

In this population-based study spanning 20 years, we saw a 15 -fold increase in the incidence of neonatal abstinence syndrome in Ontario, most of it during the last 5 years of the study period. About half of the mothers of infants with neonatal abstinence syndrome were recipients of publicly funded prescription drug coverage, and most of these women received prescriptions for opioids before and during pregnancy. The proportion of women receiving prescriptions for methadone increased as they approached delivery, whereas prescription of

\begin{tabular}{|c|c|c|c|}
\hline \multirow{3}{*}{$\begin{array}{l}\text { Drug } \\
\text { Any opioid }\end{array}$} & \multicolumn{3}{|c|}{ Time period before birth; no. (\%) } \\
\hline & $1-2 \mathrm{yr}$ & $101 \mathrm{~d}$ to $1 \mathrm{yr}$ & $100 \mathrm{~d}$ \\
\hline & $619(66.8)$ & $753(81.2)$ & $653(70.4)$ \\
\hline Opioid treatment for drug dependence & $406(43.8)$ & $570(61.5)$ & $547(59.0)$ \\
\hline Methadone only & $265(28.6)$ & $428(46.2)$ & $494(53.3)$ \\
\hline Methadone and another opioid & $141(15.2)$ & $142(15.3)$ & $53 \quad(5.7)$ \\
\hline Nonmethadone opioid* & $354(38.2)$ & $325(35.0)$ & $159(17.2)$ \\
\hline Oxycodone & $220(23.7)$ & $185(20.0)$ & $85 \quad(9.2)$ \\
\hline Hydromorphone & $33 \quad(3.6)$ & $29 \quad(3.1)$ & $(1.8)$ \\
\hline Morphine & $35 \quad(3.8)$ & $37 \quad(4.0)$ & $30 \quad(3.2)$ \\
\hline Fentanyl & $16 \quad(1.7)$ & 13 & (1.1) \\
\hline Codeine & $196(21.1)$ & $161(17.4)$ & $(5.5)$ \\
\hline Other & $11 \quad(1.2)$ & $\leq 5 \dagger$ & $\leq 5 \dagger$ \\
\hline Other psychotropic medication & $495(53.4)$ & $511(55.1)$ & $283(30.5)$ \\
\hline Sedative-hypnotic agent & $247(26.6)$ & $232(25.0)$ & $123(13.3)$ \\
\hline Barbiturates & $0 \quad(0.0)$ & $0 \quad(0.0)$ & $0 \quad(0.0)$ \\
\hline Anticonvulsant agent & $(1.7)$ & $(1.5)$ & $\leq 5 \dagger$ \\
\hline Cyclic antidepressant & 178 (19.2) & $157(16.9)$ & $38 \quad(4.1)$ \\
\hline Noncyclic antidepressant & 324 (34.9) & $312(33.7)$ & $155(16.7)$ \\
\hline Antipsychotic agent & $164 \quad(17.7)$ & $165(17.8)$ & $85 \quad(9.2)$ \\
\hline Stimulant & $34 \quad(3.7)$ & $31 \quad(3.3)$ & $(1.7)$ \\
\hline Lithium & $(1.7)$ & $17 \quad(1.8)$ & $\leq 5 \dagger$ \\
\hline
\end{tabular}


other opioids decreased, which suggests that opioid dependence during pregnancy was often recognized and appropriately treated.

In Canada, methadone is prescribed almost exclusively for opioid addiction rather than for pain. In Ontario, addiction to prescription opioids recently has supplanted heroin addiction as the most common reason to start treatment with methadone. ${ }^{21}$ This observation raises the possibility that most of the pregnant women receiving methadone in our study had prescription opioid dependence. Collectively, these observations suggest that the prescribing of opioids for chronic pain is a risk factor for addiction and the subsequent need for methadone treatment during pregnancy, leading to infants born with neonatal opioid withdrawal.

Two previous studies documenting a similar increase in the incidence of neonatal abstinence syndrome in the United States did not have access to antenatal prescribing records. ${ }^{6,13}$ Using an analysis of hospital discharge data, Creanga and colleagues ${ }^{13}$ found that $41.7 \%$ of infants with a diagnosis of neo- natal abstinence syndrome in Washington state in 2008 had been exposed to opioids. Furthermore, they found that the type of drugs to which infants were exposed was unknown in about half of those with that diagnosis. In contrast, in the subset of women for whom we had antenatal prescribing data, we found that $70 \%$ of infants with a diagnosis of neonatal abstinence syndrome were born to mothers who had received at least 1 prescription for opioids in the 100 days before delivery. The proportion of infants exposed to opioids in this subset would almost certainly be greater than $70 \%$, because exposure to heroin and other opioids can occur without a prescription. In addition to showing that the incidence of neonatal abstinence syndrome in the United States increased from 1.20 per 1000 births in 2000 to 3.39 per 1000 births in 2009, Patrick and colleagues ${ }^{6}$ found that infants with neonatal abstinence syndrome were more likely to have low birth weight and respiratory complications.

Prescribers should consider the risks of addiction and subsequent neonatal opioid withdrawal before starting opioid

Table 2: Characteristics of mothers who were beneficiaries of the public drug plan and their infants in cases of neonatal abstinence syndrome, Jan. 1, 2007, to Dec. 31, 2010

\begin{tabular}{|c|c|c|c|}
\hline \multirow[b]{2}{*}{ Characteristic } & \multicolumn{2}{|c|}{ No. $(\%)^{*}$} & \multirow[b]{2}{*}{$p$ value } \\
\hline & $\begin{array}{c}\text { Opioids prescribed in the } \\
100 \mathrm{~d} \text { before birth } \\
n=421\end{array}$ & $\begin{array}{l}\text { Opioids not prescribed in the } \\
100 \mathrm{~d} \text { before birth } \\
n=197\end{array}$ & \\
\hline \multicolumn{4}{|l|}{ Infants } \\
\hline Gestational age, wk, median (IQR) & $39(37-40)$ & $38(37-40)$ & 0.15 \\
\hline Birth weight, g, median (IQR) & $2990(2685-3391)$ & 2947 (2615-3370) & 0.28 \\
\hline Male sex & $202(48.0)$ & $97(49.2)$ & 0.77 \\
\hline \multicolumn{4}{|l|}{ Mothers } \\
\hline Age, yr, median (IQR) & $27.5(24.5-31.8)$ & $27.8(24.7-32.3)$ & 0.46 \\
\hline Cesarean delivery & $127(30.2)$ & $43(21.8)$ & 0.03 \\
\hline \multicolumn{4}{|l|}{ Neighbourhood income quintile } \\
\hline Lowest & $210(50.0)$ & $83(42.1)$ & 0.07 \\
\hline Second lowest & $83(19.7)$ & $50(25.4)$ & 0.11 \\
\hline Middle & $58(13.8)$ & $31(15.7)$ & 0.52 \\
\hline Second highest & $38(9.0)$ & $19(9.6)$ & 0.80 \\
\hline Highest & $31(7.4)$ & $12(6.1)$ & 0.56 \\
\hline \multicolumn{4}{|l|}{ First NAS-related admission to hospital } \\
\hline Birth & $396(94.1)$ & $175(88.8)$ & 0.02 \\
\hline Infant admission to NICU & $339(80.5)$ & $155(78.7)$ & 0.59 \\
\hline Length of stay, d, median (IQR) & $19(9-31)$ & $10(5-20)$ & $<0.0001$ \\
\hline \multicolumn{4}{|l|}{ Year following birth (infant) } \\
\hline Mortality & $\leq 5 \dagger$ & $0(0.0)$ & NA \\
\hline Outpatient physician encounters, median (IQR) & $25(16-38)$ & $17(12-27)$ & $<0.001$ \\
\hline Admissions to hospital, no., median (IQR) & $1(1-1)$ & $1(1-1)$ & 0.834 \\
\hline Visits to emergency department, no., median (IQR) & $1(0-2)$ & $0(0-2)$ & 0.004 \\
\hline
\end{tabular}


therapy for chronic noncancer pain, particularly for women of childbearing age. To support this practice, the Food and Drug Administration has implemented a black-box warning that states opioid dependence in pregnancy is likely to result in neonatal opioid withdrawal, but Health Canada has yet to follow suit. ${ }^{22}$

\section{Limitations}

We relied on administrative data to determine whether an infant had symptoms of neonatal opioid withdrawal. More physicians now are aware of the diagnosis of neonatal abstinence syndrome than 20 years ago, and the increased incidence that we saw may be an artifact of greater awareness. Conversely, however, neonatal opioid withdrawal may still be underrecognized, particularly when symptoms are mild and the infant does not require pharmacologic treatment or admission to an intensive care unit. ${ }^{23}$

We only had access to antenatal prescription records for a subset of the study population. Although this subset has different socioeconomic characteristics than the rest of the population, it accounted for nearly half of the cases of neonatal abstinence syndrome in Ontario.

We are unable to confirm the indication for prescribing methadone in our cohort. All but 5 of the 242142 prescriptions were for methadone solution, which is used exclusively for opioid dependence. ${ }^{24,25,26}$

Although the diagnosis of neonatal abstinence syndrome is most commonly used when an infant undergoes opioid withdrawal, some of the cases we identified in our study may have represented withdrawal from other psychotropic medications. In addition, our reliance on antenatal prescribing records meant that we were unable to determine which opioids women were using and when they used them. In particular, we have no information about heroin use or drug diversion. However, complications of heroin use in Ontario were much less common than complications of prescription opioid use during the study period..$^{21,27}$ Nevertheless, the opioid prescribed to a particular woman whose baby subsequently had neonatal opioid withdrawal may have differed from the opioid that actually caused the syndrome. Furthermore, we did not have information regarding buprenorphine use, because the formulation of buprenorphine that is used during pregnancy is only available through a special federal program in Canada. ${ }^{8}$ However, for this same reason, it is likely that buprenorphine would have been prescribed to a very small number of the women in our study.

Finally, although more than half of the women in this study likely had a mental health condition for which they received treatment with a psychotropic medication in the 1-2 years before delivery, we did not examine other chronic health conditions and pharmacotherapy that may have confounded the differences in outcomes.

\section{Conclusion}

We saw a considerable increase in the number of infants born with neonatal abstinence syndrome over a 20 -year period in Ontario, particularly during the last 5 years of the period under study. In a large and relevant contemporary subset, we found that a substantial proportion of women who deliver babies with neonatal opioid withdrawal have opioids prescribed for the treatment of chronic pain before and during pregnancy. Our results support the need for strategies to reduce the incidence of neonatal opioid withdrawal.

\section{References}

1. Hudak ML, Tan RC; Committee on Drugs; Committee on Fetus and Newborn; American Academy of Pediatrics. Neonatal drug withdrawal. Pediatrics 2012;129:e540-60.

2. Jansson LM, Velez M. Neonatal abstinence syndrome. Curr Opin Pediatr 2012;24:252-8.

3. Kandall SR, Albin S, Gartner LM, et al. The narcotic-dependent mother: fetal and neonatal consequences. Early Hum Dev 1977;1:159-69.

4. Hulse GK, Milne E, English DR, et al. Assessing the relationship between maternal opiate use and neonatal mortality. Addiction 1998;93:1033-42.

5. Abrahams RR, Kelly SA, Payne S, et al. Rooming-in compared with standard care for newborns of mothers using methadone or heroin. Can Fam Physician 2007;53:1722-30.

6. Patrick SW, Schumacher RE, Benneyworth BD, et al. Neonatal abstinence syndrome and associated health care expenditures: United States, 2000-2009. fAMA 2012;307:1934-40.

7. Letter to Food and Drug Administration from the National Association of Attorneys General. 2013 Available: www.attorneygeneral.gov/uploadedFiles /Press/FDA_NAS_Warning_Label_Letter.pdf (accessed 2013 May 29,).

8. Dow K, Ordean A, Murphy-Oikonen J, et al. Neonatal abstinence syndrome clinical practice guidelines for Ontario. 7 Popul Ther Clin Pharmacol 2012; 19:e488-506.

9. Hayes MJ, Brown MS. Epidemic of prescription opiate abuse and neonatal abstinence. 7AMA 2012;307:1974-5.

10. Alroomi LG, Davidson J, Evans TJ, et al. Maternal narcotic abuse and the newborn. Arch Dis Child 1988;63:81-3.

11. Bunikowski R, Grimmer I, Heiser A, et al. Neurodevelopmental outcome after prenatal exposure to opiates. Eur 7 Pediatr 1998;157:724-30.

12. Okie S. A flood of opioids, a rising tide of deaths. $N$ Engl 7 Med 2010;363:1981-5.

13. Creanga AA, Sabel JC, Ko JY, et al. Maternal drug use and its effect on neonates: a population-based study in Washington State. Obstet Gynecol 2012; 119:924-33.

14. Kellogg A, Rose $\mathrm{CH}, \mathrm{Harms} \mathrm{RH}$, et al. Current trends in narcotic use in pregnancy and neonatal outcomes. Am 7 Obstet Gynecol 2011;204:259e1-4.

15. Carter AA, Gomes T, Camacho X, et al. Risk of incident diabetes among patients treated with statins: population based study. BM7 2013;346:f2610.

16. Dhalla IA, Gomes T, Yao Z, et al. Chlorthalidone versus hydrochlorothiazide for the treatment of hypertension in older adults: a population-based cohort study. Ann Intern Med 2013;158:447-55.

17. Juurlink DN, Gomes T, Guttmann A, et al. Postpartum maternal codeine therapy and the risk of adverse neonatal outcomes: a retrospective cohort study. Clin Toxicol (Phila) 2012;50:390-5.

18. Gomes T, Mamdani MM, Dhalla IA, et al. Opioid dose and drug-related mortality in patients with nonmalignant pain. Arch Intern Med 2011;171: 686-91.

19. Campitelli MA, Inoue M, Calzavara AJ, et al. Low rates of influenza immunization in young children under Ontario's universal influenza immunization program. Pediatrics 2012;129:e1421-30.

20. Guttmann A, Manuel D, Stukel TA, et al. Immunization coverage among young children of urban immigrant mothers: findings from a universal health care system. Ambul Pediatr 2008;8:205-9.

21. Sproule B, Brands B, Li S, et al. Changing patterns in opioid addiction: characterizing users of oxycodone and other opioids. Can Fam Physician 2009;55: 68-69, 69e1-5.

22. FDA announces safety labeling changes and postmarket study requirements for extended-release and long-acting opioid analgesics [news release]. Silver Spring (MD): United States Food and Drug Administration; 2013. Available: www.fda.gov/NewsEvents/Newsroom/PressAnnouncements/ucm367726.htm (accessed 2013 Oct. 8)

23. Burns L, Mattick RP. Using population data to examine the prevalence and correlates of neonatal abstinence syndrome. Drug Alcohol Rev 2007;26:487-92.

24. College of Physicians and Surgeons of Ontario. Methadone maintenance treatment program standards and clinical guidelines. 4th ed. Toronto: College of Physicians and Surgeons of Ontario; 2011.

25. Ministry of Health and Long-term Care (Exceptional Access Program). Telephone Request Service Reimbursement Criteria. Toronto: Ministry of Health and Long-term Care; 2015.

26. Health Canada. Methadone Program. Ottawa: Health Canada; 2011. Available: www.hc-sc.gc.ca/hc-ps/substancontrol/exemptions/methadone-eng.php (accessed 2015 Jan 26. 2015). 
27. Dhalla IA, Mamdani MM, Sivilotti MLA, et al. Prescribing of opioid analgesics and related mortality before and after the introduction of long-acting oxycodone. CMAF 2009;181:891-6.

Affiliations: Department of Family and Community Medicine (Turner), St. Michael's Hospital; Li KaShing Knowledge Institute (Gomes, Mamdani), St. Michael's Hospital; Institute for Clinical Evaluative Sciences (Gomes, Camacho, Yao, Guttmann, Mamdani, Juurlink, Dhalla); Leslie Dan Faculty of Pharmacy (Gomes, Mamdani), University of Toronto; Division of Paediatric Medicine (Guttmann), Hospital for Sick Children; Institute of Health Policy (Guttmann), Management and Evaluation, University of Toronto; Department of Medicine (Juurlink, Dhalla), University of Toronto; Sunnybrook Research Institute (Juurlink), Toronto, Ont.; Department of Medicine (Dhalla), St. Michael's Hospital, Toronto, Ont.

Contributors: Suzanne Turner, Tara Gomes, Astrid Guttmann, David Juurlink and Irfan Dhalla contributed to the conception and design of the study. Tara Gomes, Ximena Camacho and Zhan Yao acquired, analyzed and interpreted the. Suzanne Turner, Astrid Guttmann, Muhammad Mamdani, David Juurlink and Irfan Dhalla analyzed and interpreted the data. All of the authors helped draft and revise the article, approved the final version submitted for publication and agreed to act as guarantors of the work. Suzanne Turner and Irfan Dhalla had full access to all of the data in the study and take responsibility for the integrity of the data and the accuracy of the analysis.

Funding: This study was funded by a grant from the Ontario Ministry of Health and Long-Term Care to the Ontario Drug Policy Research Net- work, which is led by Tara Gomes, Muhammad Mamdani and David Juurlink. The project was supported by the Institute for Clinical Evaluative Sciences, which is funded by an annual grant from the Ontario Ministry of Health and Long-Term Care. Irfan Dhalla is supported by a New Investigator Award and Astrid Guttmann by an Applied Chair in Child Health Policy Research, both from the Canadian Institutes of Health Research. The funders had no involvement in the design and conduct of the study; collection, management, analysis, and interpretation of the data; and preparation, review, or approval of the manuscript. The opinions, results and conclusions reported in this paper are those of the authors, and are independent from the funding sources. No endorsement by the Institute for Clinical Evaluative Sciences or the Ontario Ministry of Health and Long-Term Care is intended or should be inferred.

Competing interests: Tara Gomes reports grants from the Ontario Ministry of Health and Long-Term Care outside of the submitted work. Muhammad Mamdani has served on advisory boards for Hoffman La Roche, GlaxoSmithKline, Eli Lilly and Company, Bristol-Myers Squibb, Novartis, Novo Nordisk, AstraZeneca and Pfizer. Irfan Dhalla is a member of the national Advisory Council of Prescription Drug Misuse; he is not paid for attending committee meetings. No other competing interests were declared.

Acknowledgments: The authors thank Brogan Inc., Ottawa, for use of their Drug Product and Therapeutic Class Database.

Supplemental information: For reviewer comments and the original submission of this manuscript, please see www.cmajopen.ca/content/3/1 /E55/suppl/DC1 